\title{
Urinary incontinence during sexual intercourse
}

\author{
BOGDAN GEORGE ILEANA, (1) RENATA CIOBANU, (1) TRAIAN ENACHE
}

Prof Dr Panait Sarbu Obstetrics and Gynaecology Hospital, Bucharest, Romania

\begin{abstract}
In the present review, based on the literature data search, we suggest the urinary incontinence during sexual intercourse is an under-reported disorder among women with urinary incontinence. Urinary incontinence during sexual intercourse is defined as "complaint of involuntary loss of urine during coitus" according to the International Urogynecological Association and the International Continence Society in 2010.

This review was conducted by screening and gathering results of research papers from PubMed and Medscape. External sources were not used. Relevant studies were searched by using keywords: urinary leakage during sexual intercourse, coital incontinence, urinary incontinence during sexual intercourse, female urinary incontinence during intercourse.

In PubMed we found 14 articles of which 8 included only an abstract. In Medscape we have found 1 article. In the end only six articles were appropriate for analysis.

Finally, based on literature screening we find that, the prevalence of coital incontinence in women with urinary incontinence was high. We sustain the fact that urinary incontinence during sexual intercourse is a disease that can affect sexual life and is under-reported.

Keywords: Urinary incontinence; urinary continence; coital urinary incontinence; female urinary incontinence during intercourse

\section{INTRODUCTION}

Urinary incontinence during sexual intercourse is an under reported disorder among women with urinary incontinence. That is a common, but under-reported symptom that adversely affects sexually-active women. ${ }^{1,2}$

Coital incontinence deserves particular focus as it is often directly associated with sexual dysfunction. Women can have urine leakage either during sexual activity, or when having an orgasm, or with both. Sexual stimulation can put pressure on the bladder or on the urethra. When combined with weakened pelvic floor muscles, this pressure can lead of stress incontinence. Urine leakage during orgasm, is often because of bladder spasm. ${ }^{1-3}$

Coital incontinence during penetration may be due to the alteration of the urethrovesical angle and elevation of the bladder neck by the erect penis during moments of increased intraabdominal pressure. The mechanism of urinary incontinence during orgasm is unclear. It is postulated that penile stimulation of the nerve rich area of the bladder base and trigone may trigger detrusor overactivity in those with severe overactive bladder. Alternately, stimulation of the vanilloid receptors in this area, which are reportedly increased in density in patients with urgency, may trigger detrusor contractions. ${ }^{3-5}$

Female ejaculation may also cause some women to experience an expelling of fluid at orgasm. Some researchers claim that it's only urine that is expelled, but others consider that the paraurethral glands create a fluid that is excreted during orgasm. ${ }^{2,4,6}$
\end{abstract}


The paraurethral glands, also known as the Skene's glands, come together in a cluster at the outside opening of a woman's urethra. They produce a clear or whitish fluid. This fluid may also serve to moisten both the urethra and the tissue surrounding the vagina. ${ }^{1,2,6}$

The tissue surrounding the paraurethral glands is adhered to the vagina and clitoris, and these glands can be stimulated through the vagina. Some people believe this is the controversial G-spot, or the erotic zone that is said to yield greater arousal and stronger orgasms. $1,2,6$

Risk factors for coital incontinence include severity of incontinence, obesity, parity, and anterior and posterior vaginal wall prolapse. The severity of the coital incontinence may be associated with the degree of sexual dysfunction., ${ }^{1,46}$

Several high level, large trials support the idea that pelvic floor muscle training can significantly decrease urinary-related sexual problems as well as improve sexual physiological response in the areas of desire, arousal, lubrication, orgasm, and satisfaction. These improvements may be correlated to increased pelvic muscle strength. Coital urinary incontinence was found to be improved with muscle training. Pelvic muscle training, in combination with biofeedback and occasionally transvaginal electrical stimulation, is also used to treat urgency urinary incontinence. The effect on sexual function in this population has not been extensively studied, and involves mostly small case series. $^{2,6}$

\section{Materials and methods}

\section{Literature search}

This systematic review was conducted by screening and gathering results of research papers from literature search in PubMed database and Medscape database. External sources were not used. Relevant studies were searched by using keywords: urinary incontinence during sexual intercourse, coital incontinence, coital urinary incontinence.

\section{Data extraction}

We gathered all of full text articles that met inclusion criteria. The results from six research articles that are relevant to this review were analysed.

\section{Results}

\section{Study characteristics}

We found six articles from PubMed and Medscape, we select articles only in English language and excluded articles with the texts in French and Spanish.
In the study of Grzybowska MEand Wydra $\mathrm{DG}^{3}$ coital incontinence was reported in $65.35 \%$ on women. The frequency of coital incontinence was correlated with lower educational level and higher body mass index. In that article the authors concluded that women with coital incontinence were significantly more likely to admit that fear of incontinence or fear of embarrassment restricted their sexual activity.

Another study ${ }^{1}$ involved 505 sexually active women which were consulted about the experience of coital incontinence. Of these women $56 \%$ had coital incontinence. The prevalence of coital intercourse in urinary incontinent women was high. Coital incontinence in these women was associated with abnormal urodynamic diagnosis and urethral dysfunction.

Another study ${ }^{5}$, involved 1,041 women and $53.8 \%$ had coital urinary incontinence. From all of these $8 \%$ had coital urinary incontinence at penetration, 35\% during intercourse, 9\% at orgasm, and $48 \%$ during a combination of these.

\begin{tabular}{|c|l|l|l|}
\hline \multicolumn{4}{|l|}{ Table 1. Incidence of CUI in articles reviewed } \\
\hline Article & Patients & Percent & Mean age \\
\hline 1 & 505 & $56 \%$ & - \\
\hline 2 & $\begin{array}{l}\text { Reports about CUI between } \\
1970-2008\end{array}$ & $10-27 \%$ & 53.4 \\
\hline 3 & 97 & $63.35 \%$ & - \\
\hline 4 & $\begin{array}{l}\text { Included 26 articles between } \\
1979-2016\end{array}$ & $24-66 \%$ & - \\
\hline 5 & 1,041 & $53.8 \%$ & 52.4 \\
\hline 6 & $\begin{array}{l}\text { A database of women with } \\
\text { CUI between 1991-2009 }\end{array}$ & $11.8 \%$ & 45.3 \\
\hline CUI: Coital urinary incontinence & & \multicolumn{2}{|l}{} \\
\hline
\end{tabular}

\section{Discussion}

The etiology and pathophysiological mechanism underlying the occurrence of coital urinary incontinence have proven to be complex.

In our review of six articles the mean age of appearance was between 45 and 53 years.

Coital urinary incontinence is a complex pathology with a strong negative impact on patients' quality of life. Current studies show a delay in establishing the diagnosis worldwide since the onset of symptoms.

Another purpose of this review was to quantify the percentage of patients who reported coital urinary incontinence. Some studies report prevalence of $11.8 \%$, while other studies report results of over $63 \%$.

In the future, these patients with this specific symptomatology might benefit from therapy (even surgery). This aim is to identify 
correctly the population affected, and of course to perform a complete exam, in order to assess the exact pelvic floor disorder responsible for that condition.

\section{Limitations and future suggestions}

The limitation of our study is its low number of articles referring to urinary incontinence during sexual intercourse.

\section{CONCLUSION}

In the present review the prevalence of coital incontinence in urinary incontinent women was high, studies reported high percentage of coital urinary incontinence. We conclude that the disease is under-reported. It can be an embarrassing problem that may lead to reduced sexual desire, reduced ability to achieve an orgasm, and may even be harmful to a relationship, this issue is difficult to understand and research. In fact, it is an underestimated clinical problem.

\section{Contributions}

Concept: B.G.I., R.C., T.E., Design: B.G.I., R.C., T.E., Data Collection or Processing: B.G.I., R.C., T.E., Analysis or Interpretation: B.G.I., R.C., T.E., Literature Search: B.G.I., R.C., T.E., Writing: B.G.I., R.C., T.E.

\section{Ethics}

Peer-review: Externally peer-reviewed.

\section{DISCLOSURES}

Conflict of Interest: The authors declare no conflict of interest.

Financial Disclosure: The authors declared that this study received no financial support.

\section{REFERENCES}

1. Lau HH, Huang WC, Su TH. Urinary leakage during sexual intercourse among women with incontinence: Incidence and risk factors. PLoS One 2017; 12: 0177075.

2. Serati M, Salvatore S, Uccella S, Nappi RE, Bolis P. Female urinary incontinence during intercourse: a review on an understudied problem for women's sexuality. J Sex Med 2009; 6: 40-8.

3. Grzybowska ME, Wydra DG. Coital incontinence: a factor for deteriorated health-related quality of life and sexual function in women with urodynamic stress urinary incontinence. Int Urogynecol J 2017; 28: 697-704.

4. Duralde ER, Rowen TS. Urinary Incontinence and Associated Female Sexual Dysfunction. Sex Med Rev 2017; 5: 470-85.

5. Illiano E, Mahfouz W, Giannitsas K, et al. Coital Incontinence in Women With Urinary Incontinence: An International Study. J Sex Med 2018; 15: 1456-62.

6. Madhu C, Hashim H, Enki D, Yassin M, Drake M. Coital incontinence: what can we learn from urodynamic assessment? Urology 2015; 85 : 1034-8. 